Psychology of Language and Communication 2017, Vol. 21, No. 1

DE GRUYTER

OPEN

DOI: $10.1515 /$ plc-2017-0020

\author{
SOILE LOUKUSA ${ }^{1}$, LEENA MÄKINEN ${ }^{1}$, ILARIA GABBATORE ${ }^{1,2}$, \\ PÄIVI LAUKKANEN-NEVALA ${ }^{3}$, EEVA LEINONEN $^{4}$ \\ ${ }^{1}$ University of Oulu \\ ${ }^{2}$ University of Turin \\ ${ }^{3}$ Tilastoneuvonta, Oulu \\ ${ }^{4}$ Murdoch University
}

\title{
UNDERSTANDING CONTEXTUAL AND SOCIAL MEANING IN TYPICALLY DEVELOPING FINNISH-SPEAKING FOUR- TO EIGHT-YEAR-OLD CHILDREN
}

\begin{abstract}
This study examined the development of social-pragmatic comprehension in 170 Finnish four- to eight-year-old children. The children were asked to respond to socially and contextually demanding questions targeting their social-pragmatic language processing, and to explain their correct answers in order to elicit their awareness of how they had derived the answers from the context. The results showed that the number of correct answers increased especially between the ages of four and seven years. We found that questions demanding contextual processing without mind-reading were the easiest to understand, followed by questions demanding processing of feelings of others and false beliefs. The questions demanding understanding of relevant language use and processing of contextual factors including mental states and intentions were the most challenging for the children. Between four and five years of age there was a remarkable developmental phase in children's ability to give proper explanations.
\end{abstract}

Key words: pragmatic development, theory of mind, context, inference, social-pragmatic processing

\section{Introduction}

Understanding contextual and social meaning calls for many kinds of linguistic, cognitive and social abilities, including the ability to direct attention

Address for correspondence: Soile Loukusa, Child Language Research Center, Research Unit of Logopedics, PO Box 1000, FIN-90014, University of Oulu, Finland. E-mail: soile.loukusa@oulu.fi 
to relevant factors, to inference and to understand other people's intentions, motives and emotions (Cummings, 2009; Perkins, 2007; Sperber \& Wilson, 2012). Pragmatic skills refer to a person's ability to utilize relevant contextual information in utterance interpretation and expression, in different kinds of communication situations (Sperber \& Wilson, 1995). The search for relevance is a basic feature of human cognition, and thus people automatically pay attention to information that is relevant to them and aim to use relevant utterances only. In this field of study, context is conceptualised as a complex concept including linguistic, para- and extralinguistic, physical, cultural and cognitive aspects (Mercer, 2000; Prutting, 1982; Sperber \& Wilson, 1995). In communicative situations, the ongoing conversation and subtle details of a situation shape the relevant contextual information constantly (Gibbs \& Colston, 2012). When interpreting contextual factors, the ability to inference allows the interpreter to make connections between different kinds of information and link them together (Leinonen, Letts, \& Smith, 2000; Sperber \& Wilson, 2002). Inference therefore plays a significant role in the pragmatic comprehension process, allowing the interpreter 'to fill in the gaps' between the literal meaning of an utterance and what is actually intended (Searle, 1975).

During daily communication people also need to be aware that individuals may possess differing mental perspectives and expectations that must be taken into account in order to effectively understand the meaning of the utterance (O'Neill, 2012). The ability to take into account the mental perspective of others is traditionally called Theory of Mind (ToM), defined as a person's ability to infer one's own and others' mental states, such as beliefs and intentions, and behave accordingly (Baron-Cohen, 2000; Premack \& Woodroff, 1978). In addition, communication requires the ability to interpret others' feelings - a multidimensional process involving retrieving and connecting information from different sources (e.g. verbal utterance and body language, prosody and shared knowledge). Keeping in mind that pragmatic communication in social situations requires the involvement of social cognitive factors such as ToM and interpretation of feelings, we adopt the use of the term social-pragmatic ability.

This study focuses on the development of the ability to utilize contextual information in understanding relevant language use, intentions, beliefs, and feelings. In the last decade the study of social and pragmatic abilities has increased substantially (e.g. Angeleri \& Airenti, 2014; Bosco \& Gabbatore, 2017; Loukusa, Leinonen, \& Ryder, 2007), which has led to the possibility to develop new research-based methods for assessing the development of such capabilities in typically developing (TD) children. The adopted approach, involving a close integration of social and pragmatic comprehension skills in structured assessment, is based on previous studies that suggest a strong relationship between ToM and communicative abilities (Lohmann, Tomasello, \& Meyer, 2005; Miller, 2006; Nelson, 2005; see also Hyter, 2017; Perkins, 2011). 


\section{Development of social-pragmatic comprehension}

The development of social-pragmatic comprehension involves children's increasing ability to use context and understand others' intentions in utterance interpretations. Previous studies have shown that the ability to answer questions that demand complex contextual processing, such as understanding implicit meanings, develops with age (Loukusa et al., 2007; Loukusa, Ryder, \& Leinonen, 2008; Ryder \& Leinonen, 2003). At around eight years of age children begin to pay greater attention to all of the available relevant cues, including paralinguistic aspects of communication, and they no longer focus substantially on propositional content (Bosco, Angeleri, Colle, Sacco, \& Bara, 2013; Morton \& Trehub, 2001). An earlier study by Loukusa et al. (2007) showed that at the age of seven children can connect different kinds of contextual information in order to infer the implicit meaning of an utterance. Nevertheless, even if young children cannot yet resolve the implicit meanings of contextually complex utterances, they can utilize contextual information when identifying the object of references from the context (Bezuidenhout \& Sroda, 1998; Loukusa, et al., 2007; Ryder \& Leinonen, 2003) or interpreting simple indirect utterances (Bucciarelli, Colle, \& Bara, 2003). Compared to older children, the younger ones experience more challenges in understanding the intentions of utterances when there is a discrepancy between the literal meaning and the intended one as, for example, in deceitful and ironic expressions (Bosco et al., 2013; Bosco \& Gabbatore, 2017a; Bucciarelli et al., 2003; Filippova \& Astington, 2010; Glenwright \& Pexman, 2010; Happé, 1993; Harris \& Pexman, 2003; Wilson, 2013). It has been suggested that this could reflect the level of contextual complexity and inferential processes involved in different types of contextually demanding expressions (Bosco et al., 2013; Bucciarelli et al., 2003; Loukusa et al., 2007; Loukusa et al., 2008). The developmental trend shown in children's performance on different types of pragmatically challenging tasks (e.g. Bosco et al., 2013; Bucciarelli et al., 2003) suggests that the assessment of children's social-pragmatic performance should include questions requiring different kinds of contextual processing in order to get a holistic picture of their social-pragmatic skills.

Previous studies also suggest a developmental relationship between pragmatic and ToM abilities, as in order to communicate successfully children need to take into account others peoples' needs (Happé, 1993; Perkins, 2007; Wilson, 2013). Nelson (2005) describes the development of ToM abilities as the process of entering into the community of minds, one which becomes evident in TD children when they start to exhibit the ability to talk about their own experiences in the past or in the future, discuss or speculate with others as to why things happen, and contemplate the reasons of why people do things. The basic understanding of others' minds is measured traditionally using the so-called false belief (FB) tasks, and seems to develop between the ages 
of three and five (Siegal \& Beattie, 1991; Wellman, Cross, \& Watson, 2001; Wellman \& Lagattuta, 2000). At this age, children are also able to infer other's knowledge based on perceptual experience (Wimmer, Hogrefe, \& Perner, 1988). At the age of five children also start to show belief based reasoning when they distinguish ideological (such as religious) beliefs from factual and preference-based beliefs (Heiphetz, Spelke, Harris, \& Banaji, 2013). ToM skills continue to develop into adolescence (Bosco, Gabbatore, \& Tirassa, 2014), and they seem to contribute to understanding the implied meanings involved in more complex communicative structures, such as sophisticated lies (Talwar, Gordon, \& Lee, 2007) and ironies (Nilsen, Glenwright, \& Huyder, 2011).

In addition to ToM, the other social cognitive factor associated with children's everyday communication skills is their ability to recognize other people's feelings and emotions. Recognition of feelings and emotions starts to develop early on with the interpretation of the caregiver's emotions from his/her clear facial expressions (Hoehl \& Striano, 2010). A sophisticated and multi-sensory ${ }^{1}$ understanding of feelings and emotions develops and manifests itself during childhood, for example, in children's responses to other's behavior and spontaneous conversation (Dunn, 1987). Since this study is focused on social-pragmatic contextual comprehension, the question of the development of feelings recognition is centered on looking at how children can utilize and connect contextual cues in order to recognize other's feelings.

The ability to reflect on one's own answers is an ability that develops over time and is connected to social-pragmatic abilities. Explaining one's answers is a verbal activity, demanding many cognitive abilities, such as recognizing the difference between action and intention (Donaldson, 1986). A study by Donaldson showed that even if already three-year-olds can distinguish between cause and effect, it is only at the age of eight that children develop the ability to use words such as 'because' and 'so' when giving deductive explanations; this finding was later supported by Loukusa et al. (2008). It was shown that even though young children succeeded in explaining some of their correct answers to pragmatically challenging questions, it was only between the ages of eight and nine when they became competent $(>80 \%)$ at explaining their correct answers.

\section{The present study}

Despite the large number of studies conducted in the field of pragmatic development (e.g. Bezuidenhout \& Stroda, 1998; Ryder \& Leinonen, 2003; Spencer, 2001), there is still a need for systematic and detailed research focused on the development of children's ability to utilize different kinds of contextual information in social-pragmatic comprehension (see also: O'Neill, 2012). Moreover, it is important to develop new, research-based social-pragmatic comprehension tasks in order to assess the ability to utilize contextual cues and understand intentions (see also: O’Neill, 2012, 2014).

\footnotetext{
1 i.e. connecting information from facial expression, body language, prosody, etc.
} 
Previous studies suggest that pragmatic abilities develop over time, and even though young children can utilize contextual information in simple familiar situations (Bezuidenhout \& Sroda, 1998; Loukusa et al., 2008), they may have difficulties with more unfamiliar and demanding tasks (Bosco et al., 2013; Bosco \& Gabbatore, 2017a, 2017b; Bucciarelli et al., 2003; Glenwright \& Pexman, 2010; Harris \& Pexman, 2003; Loukusa \& Leinonen, 2008). In this study we utilized a battery of tasks called Pragma, which enables us to investigate a wide range of social-pragmatic abilities in typically developing (TD) children. The first aim of the study is to investigate the pattern of development of social-pragmatic abilities in four to eight years old children, expecting that, in line with previous studies, such capabilities progress with age. Secondly, we aimed to investigate differences in children's performance on different kinds of social-pragmatic tasks involving: (1) Contextual inference without mind-reading (ToM), (2) Contextual inference with mind-reading (ToM), (3) Relevant language use, (4) Feelings recognition, and (5) Understanding of False Beliefs. On the basis of earlier studies (e.g. Bosco et al., 2013; Bucciarelli et al., 2003) showing that children's performance in pragmatic tasks is affected by the level of inferential and contextual complexity, we expect to observe a different pattern of performance on the different kinds of Pragma tasks.

Moreover, some earlier research (e.g. Letts \& Leinonen, 2001; Loukusa et al., 2008) shows that children's ability to explain their correct answers develops between the ages of four and eight. Thus, the third aim of this study is to broaden the knowledge about how age impacts the awareness of the comprehension processes (i.e. the ability to explain one's own answers).

A deeper understanding of the typical development of social-pragmatic comprehension is an important first step in the process of detecting difficulties and delays in clinical populations. At the moment, it is well known that social-pragmatic difficulties are common in many childhood disorders, for example in autism spectrum disorders (ASD; e.g. Angeleri, Gabbatore, Bosco, Sacco, \& Colle, 2016; Happé, 1993; Loukusa \& Moilanen, 2009), specific language impairment (SLI; e.g. Letts \& Leinonen, 2001; Ryder, Leinonen, \& Schulz, 2008), and attention deficit hyperactivity disorders (ADHD; e.g. Loukusa, 2017; Väisänen, Loukusa, Moilanen, \& Yliherva, 2014). These difficulties affect everyday communication and relationships with others. According to Conti-Ramsden and Botting (2004), pragmatic difficulties are one of the core factors contributing to social well-being issues of children with SLI. At the moment, in Finland the assessment of children's comprehension abilities is essentially based on linguistic comprehension. It is clear that without also investigating social-pragmatic comprehension it is not possible to ascertain a full picture of children's functional understanding that affects their performance in real life situations. 


\section{Method}

\section{Participants}

A total of 170 Finnish extraction, Finno-Ugric origin and monolingual Finnish four- to eight-year-old TD children ( 83 boys and 87 girls) participated in the study (Table 1). The children were recruited from day-care nurseries and mainstream schools. Participation was voluntary and confirmed by written consent by the child's parents. The Ethical Committee of the Northern Ostrobothnia Hospital District approved this study.

The parents were asked to complete a preliminary data sheet about their child's language development, and if the parents did not report any developmental diagnosis or delays, the child was included in the study. To receive background information on the children's language skills, the Token Test for Children, TTFC-2, (McGhee, Ehrler, \& DiSimoni, 2007) and the Finnish version of the Test of Word Finding, TWF-2, (German, 2000) were conducted.

Table 1. Participant characteristics

\begin{tabular}{|c|c|c|c|c|c|c|}
\hline \multirow{2}{*}{$\begin{array}{c}\text { Age group } \\
\text { (years) }\end{array}$} & \multirow{2}{*}{$N$} & \multicolumn{2}{|c|}{ Gender } & \multirow{2}{*}{$\begin{array}{l}\text { Age (years; } \\
\text { months) } \\
\text { Mean }(S D)\end{array}$} & \multirow{2}{*}{$\begin{array}{c}\text { TTFC-2 }^{1} \\
\text { Mean }(S D)\end{array}$} & \multirow{2}{*}{$\begin{array}{c}\text { TWF-2 }^{2} \\
\text { Mean (SD) }\end{array}$} \\
\hline & & Boys & Girls & & & \\
\hline 4 & 31 & 16 & 15 & $4 ; 6(0 ; 4)$ & $23.9(7.7)$ & $106.7(13.4)$ \\
\hline 5 & 34 & 16 & 18 & $5 ; 5(0 ; 3)$ & $31.1(6.5)$ & $107.2(13.6)$ \\
\hline 6 & 38 & 21 & 17 & $6 ; 6(0 ; 3)$ & $35.8(4.3)$ & $106.1(13.0)$ \\
\hline 7 & 36 & 15 & 21 & $7 ; 8(0 ; 3)$ & $37.5(3.4)$ & $89.3(11.5)$ \\
\hline 8 & 31 & 15 & 16 & $8 ; 4(0 ; 3)$ & $38.9(3.3)$ & 97.7 (13.0) \\
\hline
\end{tabular}

Note: TTFC-2': Token Test for Children, Second Edition, raw scores. The raw scores (maximum score is 46) instead of standard scores had to be used, since the test is not standardized in Finnish (there is a lack of standardized language measures in Finnish suitable for children aged from 4 to 8 years).

TWF-22: Test of Word Finding, Second Edition, standard scores 90-110 average; 80-89 low/below average; 70-79 deficient.

\section{Research methods and material}

The Pragma consists of a battery of tasks which aim to evaluate children's ability to understand contextual meanings, intentions and relevant language use. The given context consists of short verbal scenarios that are presented together with color pictures, small characters, plastic animals or a story. Furthermore, they are presented in short sections, so as to minimize memory and linguistic processing requirements. In line with earlier studies that assess pragmatic comprehension (e.g. Leinonen, Ryder, Ellis, \& Hammond, 2003; Loukusa, et al., 2007), questions and scenarios were kept as grammatically and lexically simple as possible. The materials consist of 39 questions. Correct answers require the ability to understand the implied meaning of the utterances. Some 
questions were also used in our earlier studies (e.g. Loukusa et al., 2007; Loukusa et al., 2008). They vary according to contextual utilization, social language use, and understanding of intentions, thoughts, beliefs and feelings. Being conscious of the multidimensional aspects of the processing demands of the questions in this study, we roughly classified them into categories according to the phenomenon that each question is primarily focusing on. In the Pragma tasks, different kinds of questions vary in number. Most of the questions measure contextual inference with ToM $(n=18)$ because it has been shown that these kinds of questions cause particular challenges for children with social-pragmatic difficulties, such as ASD (Loukusa \& Moilanen, 2009). Since the ability to derive a conclusion by connecting information from different sources is central in pragmatic understanding (Leinonen et al., 2000; Sperber \& Wilson, 1995), the second most common question type is Contextual inference without ToM demand $(n=10)$. The battery of tasks is composed of different question types as follows (see Table 2 for question examples).

Contextual inference with ToM demand $(n=18)$. Questions primarily focus on the child's ability to derive conclusions by connecting information from different sources (e.g. verbally given information, pictorial information and world knowledge) and taking into account others' mental states and emotions. These questions require a good knowledge of social behavior.

Contextual inference without ToM demand $(n=10)$. Questions primarily focused on the child's ability to derive a conclusion by connecting information from different sources (e.g. information given verbally, pictorial information or world knowledge).

Feelings recognition $(\boldsymbol{n}=\mathbf{5})$. Questions focused on the ability to understand feelings based on given contextual cues that are primarily verbal.

Relevant language use $(n=4)$. Questions focused on the understanding of the norms regulating the relevant language use, i.e. the ability to choose a proper way of saying something in order to achieve one's own goal and taking into account the situation; this ability requires utilizing contextual cues as well as social and world knowledge.

False belief $(\boldsymbol{n}=\mathbf{2})$. Questions focused on the ability to solve FB tasks (i.e. change-in-location task and unexpected content task). These questions evaluate the ability to understand others' mental states - often required in the understanding of pragmatically demanding scenarios.

In addition, the children were asked to give explanations for their correct answers (How do you know that?) to 13 questions in order to explore if and how the children are aware of the way they utilize context in their answers (see Table 2). 


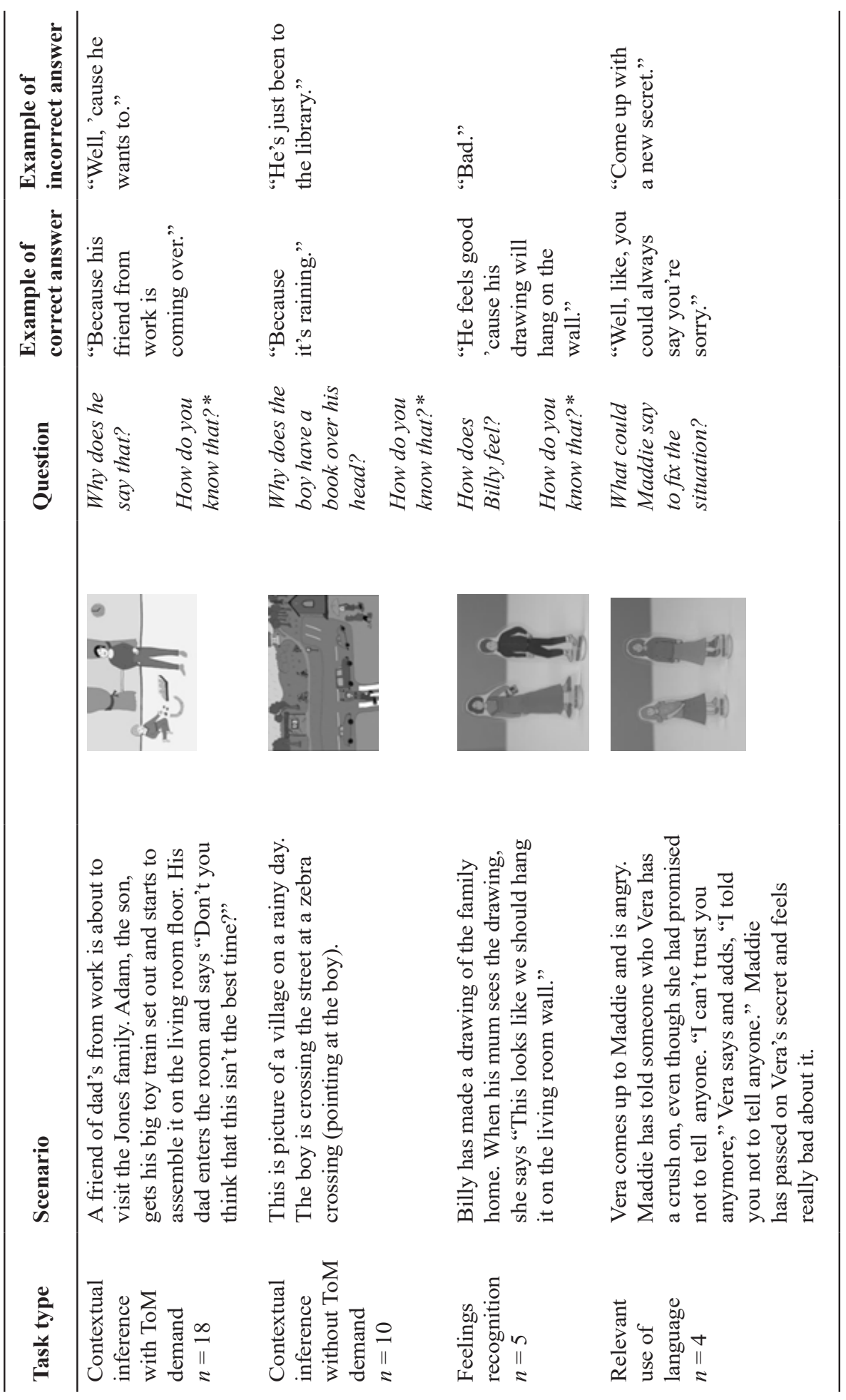




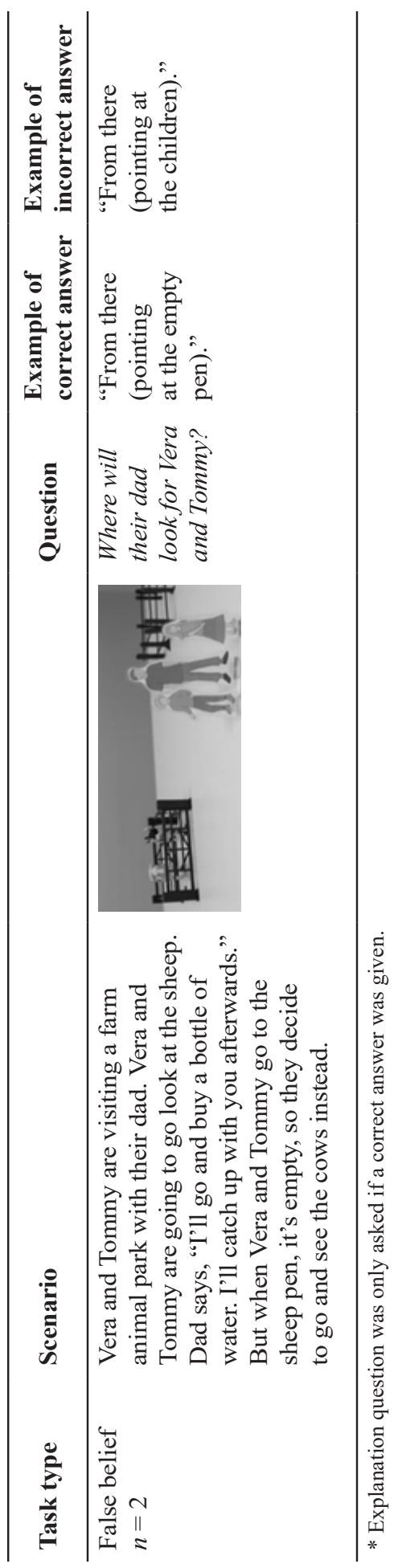


The sessions were videotaped, and the data was orthographically transcribed from the videotapes. The scoring was done from the transcriptions. An explanation question was only asked and scored if a correct answer was given to the first question, since the purpose of the explanation questions was to examine whether the child is aware of and can explicitly articulate the factors (verbal and pictorial context, world and social knowledge) that he or she has utilized in the comprehension process.

In order to check the reliability of scoring, interrater reliability (intra-class correlation coefficient) was calculated between the scores assigned by two researchers, (SL and LM), both experts in language and pragmatics. The intra-class correlation coefficient between the two raters on a sample of ten children for scoring answers was .985 , and for scoring of explanations .984 , indicating that that the scoring was reliable. Cronbach's alpha showed excellent internal consistency of the battery in answers $(\alpha=.927)$ and good internal consistency in explanations $(\alpha=.794)$.

\section{Statistical Analysis}

The relationship between age and pragmatic answer score was modelled by linear regression analysis, where age was used to predict the scores of correct answers. The value of the effect size in the relationship between age and pragmatic answer score was calculated by Pearson's correlation coefficient, and interpreted according to Cohen (1992). A one-way unrelated ANOVA was used to explore differences between age groups and post hoc tests were conducted with Tukey HSD test . The effect sizes of group comparisons were calculated using the Cohen's d. Since the explanation question was asked only if a correct answer was given, relative frequency scores (i.e. the number of incorrect explanations in proportion to correct answers) were used when analyzing explanations between groups.

\section{Results}

\section{Pragmatic answer scores}

Linear regression analysis demonstrated a significant association between age (in months) and the children's scores (Adjusted $R^{2}=0.611, p<.001$ ). The scores increased by 0.4 points $(95 \% \mathrm{CI}=0.36-0.45)$ with every month of age. The effect size for age and pragmatic answer scores was large $(r=.783)$.

After analysing age as a continuum, children were divided into different age groups, and the performance between the age groups was compared. A one-way unrelated ANOVA showed that there was a difference between age groups in answer scores $(F=67.174, p<.001, d f=4)$. Post hoc tests (Tukey HSD) showed that when comparing adjacent age groups, there was a significant difference between four- and five-year-olds $(p<.001$, Cohen's $d=1.24)$, five- and six-year-olds $(p<.001$, Cohen's $d=0.97)$ and six and 
seven-year-olds ( $p=.043$, Cohen's $d=0.68$ ). Although there was a moderate effect size in the comparison between seven- and eight-year-olds, the difference was not significant ( $p=.345$, Cohen's $d=0.61)$.

Table 3. Correct answers of different question types by age groups

\begin{tabular}{|c|c|c|c|c|c|}
\hline Question type & 4 years & 5 years & 6 years & 7 years & 8 years \\
\hline \multicolumn{6}{|c|}{$\begin{array}{l}\text { Contextual inference with ToM demand } \\
(n=18)\end{array}$} \\
\hline Mean & 4.4 & 7.9 & 11.5 & 13.7 & 14.6 \\
\hline$S D$ & 2.9 & 3.4 & 3.7 & 2.5 & 2.8 \\
\hline Abs. $f(\%)$ & 24.6 & 43.8 & 64 & 75.9 & 83.9 \\
\hline \multicolumn{6}{|c|}{$\begin{array}{l}\text { Contextual inference without ToM } \\
\text { demand }(n=10)\end{array}$} \\
\hline Mean & 6.1 & 7.7 & 8.7 & 9.1 & 9.7 \\
\hline$S D$ & 2 & 1.7 & 1.2 & 1.1 & 0.9 \\
\hline Abs. $f(\%)$ & 60.6 & 77.4 & 87.4 & 90.8 & 96.8 \\
\hline \multicolumn{6}{|c|}{ Feelings recognition $(n=5)$} \\
\hline Mean & 2.6 & 3.7 & 3.9 & 4.2 & 4.5 \\
\hline$S D$ & 1.2 & 0.8 & 1 & 0.9 & 0.77 \\
\hline Abs. $f(\%)$ & 51.6 & 73.5 & 77.9 & 83.3 & 90.3 \\
\hline \multicolumn{6}{|c|}{ Relevant use of language $(n=4)$} \\
\hline Mean & 0.8 & 1.6 & 2.2 & 3 & 3.4 \\
\hline$S D$ & 1 & 1.2 & 1.2 & 0.9 & 0.9 \\
\hline Abs. $f(\%)$ & 21 & 40.4 & 54.6 & 74.3 & 83.9 \\
\hline \multicolumn{6}{|c|}{ False Beliefs $(n=2)$} \\
\hline Mean & 0.7 & 1.3 & 1.8 & 1.8 & 1.9 \\
\hline$S D$ & 0.9 & 0.8 & 0.4 & 0.5 & 0.2 \\
\hline Abs. $f(\%)$ & 35.5 & 64.7 & 88.2 & 87.5 & 96.8 \\
\hline \multicolumn{6}{|l|}{ Total $(n=39)$} \\
\hline Mean & 14.6 & 22.2 & 28.1 & 31.6 & 34.1 \\
\hline$S D$ & 6.2 & 6.1 & 6.1 & 4 & 4.2 \\
\hline Abs. $f(\%)$ & 37.4 & 56.9 & 72.1 & 81 & 87.4 \\
\hline
\end{tabular}

Note: Absolute frequency (Abs. $f$ ) means percentage of correct answers in the question type in the age group.

\section{Comparison of different question types}

When comparing the processing demands of the different question types in general, the percentages of correct answers showed that Relevant language use and Contextual inference with ToM demand questions were the most demanding 
question types, whereas Contextual inference without ToM demand questions were the easiest ones (Table 3). The children's number of correct answers at Feelings recognition and False Belief questions fell in between the above mentioned questions.

A one-way unrelated ANOVA showed that there was a difference between age groups in all question types: Contextual inference with ToM demand $(F=59.343, p<.001, d f=4)$, Contextual inference without ToM demand $(F=29.978, p<.001, d f=4)$, Feelings recognition $(F=18.686, p<.001$, $d f=4)$, Relevant language use $(F=30.541, p<.001, d f=4)$ and False Beliefs $(F=21.364, p<.001, d f=4)$. A post hoc test (Tukey HSD) showed that, when comparing adjacent age groups, there was a significant difference in Contextual inference with ToM demand questions between four- and five-year-olds $(p<.001$, Cohen's $d=1.08)$, five- and six-year-olds $(p<.001$, Cohen's $d=1.03)$ and six- and seven-year-olds $(p=.029$, Cohen's $d=0.68)$. In Contextual inference without ToM demand questions, the difference was significant between four- and five-year-olds $(p<.001$, Cohen's $d=0.89)$ and five- and six-year-olds ( $p=.033$, Cohen's $d=0.67$ ). In Feelings recognition questions, a significant difference was found between four- and five-year-olds $(p<.001$, Cohen's $d=1.08)$, in Relevant language use questions between four- and five-year-olds ( $p=.024$, Cohen's $d=0.70$ ) and six- and seven-year-olds ( $p=.012$, Cohen's $d=0.76)$, and in False belief questions between four- and five-year-olds $(p=.001$, Cohen's $d=0.70)$ and five- and six-year-olds $(p=.011$, Cohen's $d=0.77)$.

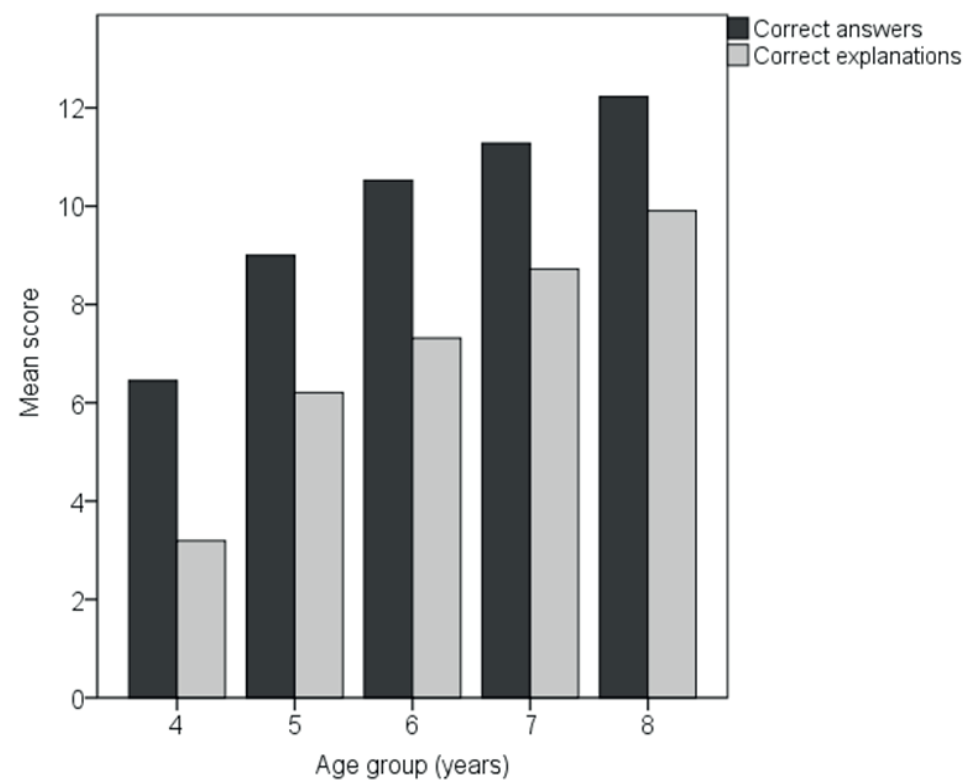

Figure 1. Mean 'score of correct answers and explanations in age groups from four to eight years. The answer score contains only scores from questions that contained follow-up questions $(\max =13)$. 


\section{Developmental trend of explanations}

Thirteen of the questions contained a follow-up question requiring an explanation, provided that the child gave a correct answer to the initial question. Therefore, to explore a child's ability to provide explanations, the number of correct answers had to be taken into account (Figure 1). Analysis of the relative frequency (number of correct explanations/ $f$ x 100\%) showed that four-yearold children were able to successfully explain $46 \%$ of their correct answers, five-year-old children - 69\%, six-year-old $-68 \%$, seven-year-old $-77 \%$ and eight-year-old $-81 \%$ of them. A one-way unrelated ANOVA showed that there was a difference between age groups in their ability to give an explanation for correct answers $(F=12.433, p<.001, d f=4)$. According to a post hoc test (Tukey HSD), this was caused by the age difference between four and five-year-olds $(p<.001)$.

\section{Discussion}

This study explored the development of the social-pragmatic comprehension abilities in four- to eight-year-old children. The ability to process contextual information and recognize others' intentions is important in many areas of children's life. Between four and eight years of age, children utilize their social-pragmatic abilities, for example, while making friends (Gertner, Rice, \& Hadley, 1994) and interacting with teachers (Edwards \& Mercer, 1986). In particular, after entering the school environment, the communicative situations that children are a part of become more complex, and the development of social-pragmatic skills helps children to interpret indirect utterances and communicate in socially accepted ways (Edwards \& Mercer, 1986). Miscommunication can result in social difficulties, including discrimination by peers (see: Conti-Ramsden \& Botting, 2004; Mackie \& Law, 2010) and, thus, children's social-pragmatic development should be assessed and supported if needed.

In this study, the age of the children was found to have an effect on their ability to answer the different types of questions and provide explanations for correct answers. In line with earlier studies (e.g. Bosco \& Gabbatore, 2017a, 2017b; Bucciarelli et al., 2003; Hudson \& Slackman, 1990; Loukusa et al., 2007, 2008), it was found that the four-year-old children found it difficult to answer questions demanding social-pragmatic understanding, while by the age of seven and eight their performance was significantly better, although there was as yet no ceiling effect. This can be interpreted as indicating that, with age, children become more capable of directing their attention towards relevant information in utterance interpretation (Loukusa et al., 2008; Ryder \& Leinonen, 2003). Development of social-pragmatic abilities is accompanied by development of various cognitive and language abilities (see Perkins, 2007, 2011). With increasing age children are more capable of managing inferential chains of different complexities (Bosco et 
al., 2013; Bosco \& Gabbatore, 2017a, 2017b; Harris \& Pexman, 2003), express complex issues explicitly (Mäkinen, Loukusa, Nieminen, Leinonen, \& Kunnari, 2014) and reason about beliefs (Heiphetz et al., 2013). In this study, we found the most significant progress in children's social-pragmatic abilities occurred between four and six years of age, which is also the period when children's ToM and other cognitive skills (e.g. self-monitoring and cognitive flexibility) are said to be developing rapidly (Diamond, 2002; Jones, Rothbart, \& Posner, 2003; Wellman et al., 2001; Wimmer \& Perner, 1983) and when children experience an increasing variety of different communicative situations (Milosky, 1992).

When children's social-pragmatic abilities develop, they become more capable of manipulating contextually and socially complex information in a relevant way (see also Vieiro \& García-Madruga, 1997). In the present study, this was particularly shown in children's increasing ability to answer questions requiring utilization of different kinds of contextual information, such as verbal and pictorial information, world knowledge, and understanding of others' minds. A developmental trend between the age groups from four and eight years of age was demonstrated in the different tasks, and specifically in the tasks that demanded the processing of contextual information with ToM. In general, the findings of this study are in line with previous studies showing that the ability to utilize contextually relevant information develops between the ages of four and eight (e.g. Loukusa \& Leinonen, 2008; Loukusa et al., 2008).

In line with earlier studies (e.g. Bosco et al., 2013; Bucciarelli et al., 2003; Loukusa et al., 2007), the present study showed that children's performance varies as a function of the contextual complexity of the task and the different degree of intentionality required. In this study, we found that questions demanding contextual processing without ToM were the easiest to understand, followed by questions demanding processing of others' feelings and false beliefs (Contextual inference without ToM demand $<$ Feelings recognition, False Beliefs $<$ Contextual inference with ToM demand, Relevant language use). Most of the questions in the study required the children to deal with contextual factors and included the understanding of mental states and intentions. The Contextual inference with ToM demand questions, together with the questions demanding understanding of relevant language use, were the most challenging for the children. These questions require children to draw conclusions on the basis of information derived from different sources as well as to have the ability to take into account mental states of others, together with a general knowledge of social norms. ToM abilities develop during school age and keep developing during adolescence (Bosco et al., 2014). It is not surprising, therefore, that questions requiring the use of complex contextual information and ToM are the most difficult questions to answer. In many real-life communicative situations, the processing of various contextual cues and ToM contributes to understanding of nonliteral meanings and intentions (see also Schmid, 2012; Sperber \& Wilson, 2012; Wilson, 2012). Developmentally, these abilities are shown in 
children's progressing ability to use relevant language according to different situations and understand what the other person really intends in different kinds of communication situations. Because these abilities have a multifactorial base, the social-pragmatic development is vulnerable to dysfunctions related to many areas of development, as mentioned previously (Cummings, 2009; Perkins, 2007, 2011).

A further focus of the present study was to investigate children's awareness of their comprehension processes by analyzing their explanations to correct answers. In this study, between the ages of four and five a developmental phase was identified in children's ability to give appropriate explanations for their correct answers (four-year-olds explained $46 \%$ and five-year-olds $69 \%$ of their answers correctly). This shows an improvement in the children's awareness of cognitive processes regulating utterance comprehension (see also Donaldson, 1986; Loukusa et al., 2008). Although, in our study, five-year-old children managed to explain most of their correct answers, it was only at the age of eight when they reached the level of $80 \%$ of correct explanations. Thus, in line with earlier findings (Letts \& Leinonen, 2001; Loukusa et al., 2008), only older children could explicitly express the information they had used in their answers. In the light of our findings, it is not surprising that earlier studies have shown that children with different kind of childhood disorders, such as ASD (Loukusa \& Moilanen, 2009), SLI (Letts \& Leinonen, 2001) and ADHD (Loukusa, 2017), have difficulties when explaining their answers even if they succeeded in deriving an answer from the context.

An accurate assessment of children's pragmatic abilities requires tasks that are sufficiently challenging in order to reproduce real-life communicative situations, often requiring utilization of many contextual factors concurrently and quickly. Pragma is an assessment tool that reflects real-life social-pragmatic demands in a simulated approach in a structured test situation, allowing the identification of developmental trajectories and detection of potential difficulties in this area of functioning. The tasks were developed with the aim to give a comprehensive picture of the child's social-pragmatic comprehension ability. In order to diminish the effects of purely linguistic skills (e.g. vocabulary and sentence structure), in line with earlier studies (Leinonen et al., 2003; Loukusa et al., 2007), the test scenarios and the questions were designed to be as linguistically simple as possible so that even the younger children would understand them. However, the linguistic complexity was not tested, which can be seen as a weakness of the study. The Pragma battery includes contextual inference questions with and without ToM demand, which make it possible to detect whether the child's social-pragmatic difficulties are more generally caused by contextual comprehension problems or only appear when understanding of the mind of others is required. Moreover, Pragma's questions have been categorized keeping in mind that social-pragmatic competence is the result of many interacting abilities (see Cummings, 2009; Gibbs \& Colston, 2012; Perkins, 2007), and 
thus the misunderstanding of utterances is not necessarily caused by only one background factor (e.g. ToM) but the interaction of different kind of factors (e.g. memory, inference, world knowledge and linguistic understanding). Therefore, when drawing conclusions about children's abilities to answer different types of questions, interaction between different categories should be taken into account (e.g. contextual inference plays a central role in understanding the feelings of others in the questions of Pragma tasks).

The method and materials used in this study enabled the investigation of the development of social-pragmatic comprehension. It would be interesting to examine their clinical validity in future studies of clinical populations. This is especially important now, when social (pragmatic) communication disorder is an accepted diagnosis in the DSM-5 (American Psychiatric Association, 2013), and it seems that in 2018 in the forthcoming ICD-11 (World Health Organization, 2016) there will be a similar diagnostic category identified as a developmental language disorder with impairment of mainly pragmatic language.

Further research concerning social-pragmatic abilities in typically developing children is still needed. Understanding developmental features in every age group allows us to better understand and support children's abilities according to their actual social-pragmatic developmental level. This is particularly relevant in the modern technology-based society, where the way of interacting with other people is constantly changing. From a very young age, children are spending increasingly more time interacting with technologies than interacting face-to-face with people. This may pose new challenges for social-pragmatic development.

\section{Acknowledgements}

First, we want to thank the large number of children and their parents, schools and nurseries who participated in this study. We thank the students of logopedics Ilona Haataja, Meeri Nurmimäki, Anniina Ruohomäki, Katja Saarinen and Kaisa Tervahauta for the help with the data collection.

This research was financially supported by the Academy of Finland.

\section{References}

American Psychiatric Association. (2013). Diagnostic and statistical manual of mental disorders (5th ed.). Washington, DC: American Psychiatric Association.

Angeleri, R., \& Airenti, G. (2014). The development of joke and irony understanding: A study with 3-to 6-year-old children. Canadian Journal of Experimental Psychology/Revue canadienne de psychologie expérimentale, 68(2), 133. Doi:10.1037/cep0000011 
Angeleri, R., Gabbatore, I., Bosco, F. M., Sacco, K., \& Colle, L. (2016). Pragmatic abilities in children and adolescents with autism spectrum disorder: A study with the ABaCo battery. Minerva Psichiatrica, 57(3), 93-103.

Baron-Cohen, S. (2000). Theory of mind and autism: A fifteen year review. In

S. Baron-Cohen, H. Tager-Flusberg, \& D. J. Cohen (Eds.), Understanding Other Minds: Perspectives from Developmental Cognitive Neuroscience (2nd ed.), (pp. 3-20). Oxford: Oxford University Press.

Bezuidenhout, A., \& Sroda, M. S. (1998). Children's use of contextual cues to resolve referential ambiguity: An application of relevance theory. Pragmatics and Cognition, 6, 265-299. Doi:10.1075/pc.6.1-2.14bez

Bosco, F. M., Angeleri, R., Colle, L., Sacco, K., \& Bara, B. G. (2013). Communicative abilities in children: An assessment through different phenomena and expressive means. Journal of Child Language, 40, 741-778. Doi: $10.1017 / \mathrm{S} 0305000913000081$

Bosco, F. M., \& Gabbatore, I. (2017a). Theory of mind in recognizing and recovering communicative failures. Applied Psycholinguistics, 38, 57-88. Doi: $10.1017 /$ S0142716416000047

Bosco, F. M., \& Gabbatore, I. (2017b). Sincere, Deceitful, and Ironic Communicative Acts and the Role of the Theory of Mind in Childhood. Frontiers in Psychology, 8, 21. Doi:10.3389/fpsyg.2017.00021

Bosco, F. M., Gabbatore, I., \& Tirassa, M. (2014). A broad assessment of theory of mind in adolescence: the complexity of mindreading. Consciousness and Cognition, 24, 84-97. Doi:10.1016/j.concog.2014.01.003

Bucciarelli, M., Colle, L., \& Bara, B. G. (2003). How children comprehend speech acts and communicative gestures. Journal of Pragmatics, 35, 207-241. Doi:10.1016/S0378-2166(02)00099-1

Cohen, J. (1992). Quantative methods in psychology. A Power Primer. Psychological Bulletin, 112, 155-159. Doi:10.1037/0033-2909.112.1.155

Conti-Ramsden, G., \& Botting, N. (2004). Social difficulties and victimization in children with SLI at 11 years of age. Journal of Speech, Language, and Hearing Research, 47, 145-161. Doi:10.1044/1092-4388(2004/013)

Cummings, L. (2009). Clinical pragmatics. Cambridge: Cambridge University Press.

Cummings, L. (2014). Pragmatic Disorders. Perspectives in Pragmatics, Philosophy \& Psychology 3. London: Springer.

Diamond, A. (2002). Normal development of prefrontal cortex from birth to young adulthood: Cognitive functions, anatomy, and biochemistry. In D. Stuss \& R. Knight (Eds.), Principles of frontal lobe function, (pp. 466-503). New York, NY: Oxford University Press.

Donaldson, M. L. (1986). Children's explanations: A psycholinguistic study. Cambridge, UK: Cambridge University Press. 
Dunn, K. (1987). Understanding feelings: the early stages. In J. Bruner \& H. Haste (Eds.), Making Sense: The Child's Construction of the World, (pp. 17-26). London: Methuen.

Edwards, D., \& Mercer, N. (1986). Context and continuity: Classroom discourse and the development of shared knowledge. In Durkin, K. (Ed.), Language Development in School Years, (pp. 172-203). London: Croom Helm.

Filippova, E. \& Astington, J. (2010). Children's understanding of social-cognitive and social-communicative aspects of discourse irony. Child Development, 81, 913-928. Doi:10.1111/j.1467-8624.2010.01442.x

German, D. J. (2000). Test of Word Finding (2nd ed.). San Antonio, TX: Pearson [Translation and standardization of the Finnish version: Niilo Mäki Instituutti, 2007].

Gertner, B. L., Rice, M. L., \& Hadley, P. A. (1994). Influence of communicative competence on peer preferences in a preschool classroom. Journal of Speech, Language, and Hearing Research, 37, 913-923.

Gibbs, R. W., \& Colston, H. I. (2012). Interpreting figurative meaning. New York, NY: Cambridge University Press.

Glenwright, M., \& Pexman, P. M. (2010). Development of children's ability to distinguish sarcasm and verbal irony. Journal of Child Language, 37, 429-451. Doi:10.1017/S0305000909009520

Happé F. G. E. (1993). Communicative competence and theory of mind in autism. A test of relevance theory. Cognition, 48, 101-109.

Harris, M., \& Pexman, P. M. (2003). Children's perceptions of the social functions of verbal irony. Discourse Processes, 36, 147-165. Doi:10.1207/ S15326950DP3603_1

Heiphetz, L., Spelke, E. S., Harris, P. L. \& Banaji, M. R. (2013). The development of reasoning about beliefs: Fact, preference, and ideology. Journal of Experimental Social Psychology, 49, 559-565. Doi:10.1016/j. jesp.2012.09.005

Hoehl, S. \& Striano, T. (2010). Infant's neural processing of positive emotions and eye gaze. Social Neuroscience, 5, 30-39. Doi:10.1080/17470910903073232

Hudson, J. A., \& Slackman, E. A. (1990). Children's use of scripts in inferential text processing. Discourse Processes, 13, 375-386. Doi: $10.1080 / 01638539009544766$

Hyter, Y. (2017). Pragmatic Assessment and Intervention in Children. In L. Cummings (Ed.), Research in Clinical Pragmatics (pp. 493-526). Series: Perspectives in Pragmatics, Philosophy \& Psychology, Vol. 11, Cham, Switzerland: Springer-Verlag.

Jones, L. B., Rothbart, M. K., \& Posner, M. I. (2003). Development of executive attention in preschool children. Developmental Science, 6, 498-504. Doi:10.1111/1467-7687.00307

Leinonen, E., Letts, C., \& Smith, B. R. (2000). Children's Pragmatic Communication Difficulties. London: Whurr Publishers. 
Leinonen, E., Ryder, N., Ellis, M., \& Hammond, C. (2003). The use of context in pragmatic comprehension by specifically language-impaired and control children. Linguistics, 41-2, 407-423. Doi:10.1515/ling.2003.014

Letts, C., \& Leinonen, E. (2001). Comprehension of inferential meaning in language-impaired and language normal children. International Journal of Language and Communication Disorder, 36, 307-328. Doi:10.1080/13682820110045829

Lohmann, H., Tomasello, M., \& Meyer, S. (2005). Linguistic communication and social understanding. In J. W. Astington \& J. A. Baird. Why Language Matters for Theory of Mind (pp. 245-265). New York, NY: Oxford University Press.

Loukusa, S. (2017). Attention deficit hyperactivity disorder. In L. Cummings (Ed.), Research in Clinical Pragmatics, (pp. 85-107), Series: Perspectives in Pragmatics, Philosophy \& Psychology, Vol. 11, Cham: Springer-Verlag.

Loukusa, S., \& Leinonen, E. (2008). Development of comprehension of ironic utterances in 3- to 9-year-old Finnish-speaking children. Psychology of Language and Communication, 12, 55-69. Doi:10.2478/v10057-008-0003-0

Loukusa, S., Leinonen, E., \& Ryder, N. (2007). Development of pragmatic language comprehension in Finnish-speaking children. First Language, 27, 281-298. Doi:10.1177/0142723707076568

Loukusa, S., \& Moilanen, I. (2009). Pragmatic inference abilities in individuals with Asperger syndrome or high-functioning autism. A review. Research in Autism Spectrum Disorders, 3, 890-904. Doi:10.1016/j.rasd.2009.05.002

Loukusa, S., Ryder, N., \& Leinonen, E. (2008). Answering questions and explaining answers: A study of Finnish-speaking children. Journal of Psycholinguistic Research, 37, 219-241. Doi:10.1007/s10936-007-9067-6

Mackie, L., \& Law, J. (2010). Pragmatic language and the child with emotional/ behavioural difficulties (EBD): A pilot study exploring the interaction between behaviour and communication disability. International journal of language \& communication disorders, 45, 397-410. Doi:10.3109/ 13682820903105137

McGhee, R., Ehrler, D. J., \& DiSimoni, F. (2007). Token test for children (2nd ed.). Austin, TX: Pro-Ed.

Mercer, N. (2000). Words and Minds: How We Use Language to Think Together. London: Routledge.

Miller, C. A. (2006). Developmental relationships between language and theory of mind (tutorial). American Journal of Speech-Language Pathology, 15, 142-154. Doi:10.1044/1058-0360(2006/014)

Milosky, L. M. (1992). Children listening: The role of world knowledge in language comprehension. In R. S. Chapman (Ed.), Processes in language acquisition and disorders, (pp. 20-44). St Louis, MO: Mosby-Year Book.

Morton, J. B. \& Trehub, S. E. (2001). Children's understanding of emotion in speech. Child Development, 72, 834-43. Doi:10.1111/1467-8624.00318 
Mäkinen, L., Loukusa, S., Nieminen, L., Leinonen, E., \& Kunnari, S. (2014). The development of narrative productivity, syntactic complexity, referential cohesion, and event content in four- to eight-year-old Finnish children. First Language, 34, 24-42. Doi:10.1177/0142723713511000

Nelson, K., (2005). Language pathways into the community of minds. In J. W. Astington \& J. A. Baird (Eds.), Why Language Matters for Theory of Mind (pp. 26-49). New York, NY: Oxford University Press.

Nilsen, E. S., Glenwright, M., \& Huyder, V. (2011). Children and adults understand that verbal irony interpretation depends on listener knowledge. Journal of Cognition and Development, 12, 374-409. Doi:10.1080/152483 72.2010 .544693

O'Neill, D. K. (2014). Assessing pragmatic language functioning in young children: Its importance and challenges. In D. Matthews (Ed.), Pragmatic development in first language acquisition (pp. 363-386). Amsterdam: John Benjamins.

O'Neill, D. K. (2012). Components of pragmatic ability and children's pragmatic language development. In H.-J. Schmid (Ed.), Cognitive pragmatics (pp. 261-287). Berlin: De Gruyter.

Perkins, M. R. (2011) Clinical pragmatics. In J-O Östman \& J. Verschueren (Eds.), Pragmatics in Practice (pp. 66-92). Amsterdam: John Benjamins.

Perkins, M. (2007). Pragmatic impairment. Cambridge: Cambridge University Press.

Premack, D. \& Woodroff, G. (1978). Does the chimpanzee have a "theory of mind"? Behavioral and Brain Sciences, 4, 515-526. Doi:10.1017/ S0140525X00076512

Prutting, C. A. (1982). Pragmatics as social competence. Journal of Speech and Hearing Disorders, 47, 123-134. Doi:10.1044/jshd.4702.123

Ryder, N., \& Leinonen, E. (2003). Use of context in question answering by 3-, 4and 5-year-old children. Journal of Psycholinguistic Research, 32, 397-415. Doi:10.1023/A:1024847529077

Ryder, N., Leinonen, E., \& Schulz, J. A. (2008). Cognitive approach to assessing pragmatic language comprehension in children with specific language impairment. International Journal of Language \& Communication Disorders, 43, 427-447. Doi:10.1080/13682820701633207

Schmid, H.-J. (2012). Generalizing the apparently ungeneralizable. Basic ingredients of a cognitive-pragmatic approach to the construal of meaningin-context. In H.-J. Schmid (Ed.), Cognitive pragmatics (pp. 3-22). Berlin: De Gruyter.

Searle, J. R. (1975). Indirect speech acts. In P. Cole \& J. L. Morgan (Eds). Syntax and Semantics. Volume 3: Speech Acts, (pp. 59-82). San Diego, CA: Academic Press.

Siegal, M. \& Beattie, K. (1991). Where to look first for children's knowledge of false beliefs. Cognition, 38, 1-12. Doi:10.1016/0010-0277(91)90020-5 
Spencer, K. D. (2001). Broadening the units of analysis in communication: speech and nonverbal behaviours in pragmatic comprehension. Journal of Child Language, 28, 325-349. Doi:10.1017/S0305000901004664

Sperber, D., \& Wilson, D. (2012). Introduction: pragmatics. In D. Wilson \& S. Sperber (Eds.), Meaning and relevance (pp. 1-27). Cambridge: Cambridge University Press.

Sperber, D., \& Wilson, D. (1995). Relevance: Communication and cognition (2nd ed.). Oxford: Basil Blackwell.

Talwar, V., Gordon, H. M., \& Lee, K. (2007). Lying in the elementary school years: verbal deception and its relation to second-order belief understanding. Developmental Psychology, 43, 804-810. Doi:10.1037/0012-1649.43.3.804

Vieiro, P., \& García-Madruga, J. A. (1997). An analysis of story comprehension through spoken and written summaries in school-age children. Reading and Writing: An Interdisciplinary Journal, 9, 41-53. Doi:10.1023/A:1007932429184

Väisänen, R., Loukusa, S., Moilanen, I., \& Yliherva, A. (2014). Language and pragmatic profile in children with ADHD measured by Children's Communication Checklist 2nd edition. Logopedics Phoniatrics Vocology, 39, 179-187. Doi:10.3109/14015439.2013.784802

Wellman, H. M., Cross, D., \& Watson, J. (2001). Meta-analysis of theory-ofmind development: The truth about false belief. Child Development, 72, 655-684. Doi:10.1111/1467-8624.00304

Wellman, H. M., \& Lagattuta, K. H. (2000). Developing understanding of mind. In S. Baron-Cohen, H. Tager-Flusberg, \& D. J. Cohen (Eds), Understanding Other Minds: Perspectives from Developmental Cognitive Neuroscience (2nd ed.), 21-49. Oxford: Oxford University Press.

Wimmer, H., Hogrefe, G.-J., \& Perner, J. (1988). Children's understanding of informational access as source of knowledge. Child Development, 59, 386-396. Doi:10.2307/1130318

Wimmer, H., \& Perner, J. (1983). Beliefs about beliefs: Representation and constraining function of wrong beliefs in young children's understanding of deception. Cognition, 13, 103-128. Doi:10.1016/0010-0277(83)90004-5

Wilson, D. (2012). Metarepresentation in linguistic communication. In D. Wilson \& S. Sperber (Eds.), Meaning and relevance (pp. 230-258). Cambridge: Cambridge University Press.

Wilson, D. (2013). Irony comprehension: A developmental perspective. Journal of Pragmatics, 59, 40-56. Doi:10.1016/j.pragma.2012.09.016

World Health Organisation (2016). International Classification of Diseases, 11th revision (ICD-11). Retrieved June 6, 2016, from http://www.who.int/ classifications/icd/revision/en/ 